\title{
TOPOGRAPHIC FEATURES OF MALYY NARYN RIVER WATERSHED BASED ON DIFFERENT DATA
}

\author{
Li Mengmeng ${ }^{1, *}$, Chen Lijun², Cui Yajun ${ }^{1}$, Zhang Mengyuan ${ }^{1}$ \\ ${ }^{1}$ China University of Mining and Technology, Beijing 100083, China-776971792@qq.com \\ ${ }^{2}$ National Geomatics Center of China, Beijing 100830, China \\ Commission III , WG III/IVb
}

KEY WORDS: ZY3 DSM, SRTM DEM, ASTER GDEM, Topographic Features, Slop, HI, River Network Density, River Network Discrepancy

\begin{abstract}
:
This paper researched the influence on the topographical characteristics of watersheds by setting different catchment area thresholds based on different data sets, namely ZY3 DSM, SRTM DEM and ASTER GDEM. Slope, hypsometric integral, river network density and river network discrepancy are analyzed and compared. The results are as follows: a) Three data sets all can express the same rough terrain characteristics and the same degree of watershed topography development; b) ZY3 DSM can reflect terrain information over the Malyy Naryn River watershed in most detail and it has the best expression effect on the terrain among the three data sets of ZY3 DSM, SRTM DEM and ASTER GDEM, followed by SRTM DEM, and the effect of ASTER GDEM is the worst; c) The similarity of river networks extracted by ZY3 DSM and SRTM DEM is the highest, and the similarity between ZY3 DSM and ASTER GDEM is the lowest one.
\end{abstract}

\section{INTRODUCTION}

Digital Elevation Model (DEM) and Digital Surface Model (DSM) are both digital expression of surface of earth and the basic data of digital terrain analysis. With the development of spatial data acquisition technology, high-precision terrain data at large areas can be acquired rapidly.

DSM and DEM are widely used in watershed hydrology. At present, SRTM DEM and ASTER GDEM are two data sources which are studied mostly. Some scholars (Guo et al., 2011; Ma et al., 2011; Wu et al., 2017; Ren et al., 2018) studied the terrain information expression of SRTM DEM and ASTER GDEM. Furthermore, other scholars(Thomas et al., 2014; Solomon Vimal, 2012) extracted the river network and terrain feature factors from SRTM and ASTER, and obtained the suitability of the two DEM data sets in terrain information expression. All of the studies above regarded measured topographic maps as true values and river networks were extracted under a single catchment area threshold. However, with the launch of the Ziyuan-3(ZY3) surveying satellite and the emergence of a large number of ZY3 DSM, the differences on topography analysis among ZY3 DSM and two data sets mentioned above in watershed without topographic maps remain to be explored.

\section{OVERVIEW OF STUDY AREA AND DATA SETS}

\subsection{The study area}

The Malyy naryn river catchment was selected as the study area. It is located in Kyrgyzstan and belongs to the Naryn
River catchment. The area is about $3887 \mathrm{~km}^{2}$ and the elevation difference is around 2630 meter. There are many high mountains in the study area, and the terrain is complex, lying northeast to southwest tilt, shown as figure1. Water supply of the Malyy Naryn River mostly come from glacier.

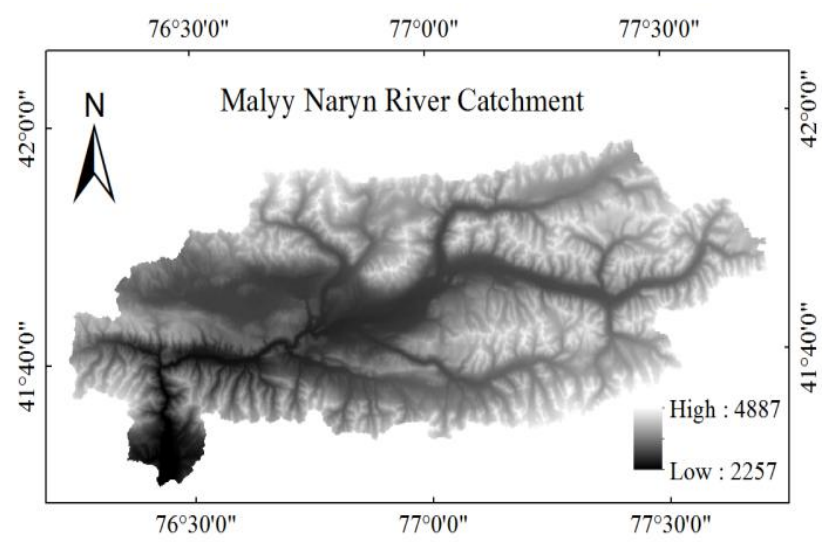

Figure 1. Location of the study area

\subsection{Data sets}

This paper analyzed the differences on catchments terrain characteristics extracted from the three data sets of ZY3 DSM, SRTM DEM and ASTER GDEM.

The Ziyuan-3 surveying satellite is the first civilian highresolution stereo mapping satellite of China. National Geomatics Center of China has produced a large number of 10 meter resolution outside Digital Surface Model using ZY3 satellite images by Multi-baseline, multi-features automatic

\footnotetext{
* Corresponding author
} 
matching extraction technology(Tang et al., 2012; Li, 2012), hereinafter referred to as ZY3 DSM.

The SRTM DEM, Shuttle Radar Torpography Mission Digital Elevation Model, is a kind of land surface radar image data sets measured by the NASA and the National Mapping Agency of the Department of Defense (NIMA) and Completed by SRTM system loaded on the Endeavor space shuttle launched by the United States. This data sets covers 80 percent of the Earth's land between 60 degrees north latitude and 60 degrees south latitude. It has two versions, one version's spatial resolution is 90 meter,the other one's is 30 meter. This study chose the later one, namely SRTM1, referred to as SRTM.

The ASTER GDEM, Advanced Space-borne Thermal Emission and Reflection Radiometer Global Digital Elevation Model, is a 30 meter resolution global Digital Elevation Model, posted by NASA and Japan's Ministry of Economy, Trade and Industry in June 2009. It covers 99 percent of the Earth's land, between 83 degrees north latitude and 83 degrees south latitude, so it is the most widely covered data sets currently. At present, there are two versions about ASTER GDEM,and ASTER GDEM V2 was issued on January 6, 2015.In this paper, we chose ASTER GDEM V2 as the third data set, referred to as ASTER.

\section{METHOD AND PROCESS}

There are many topographic features extraction algorithms based on DEM, but the surface flow runoff simulation algorithm is widely used in DEM-based basin features extraction currently (O'Callaghan and Mark, 1984). It involves fallowing parts:

(1) Filling sinks: there are some "spurious sinks" in DEM sets because of the impact of data noise and interpolation methods, "spurious sinks" can lead to poor drainage in watershed, which will hinder DEM from generating complete stream networks. In this experiment, the model Fill Sinks in the ArcHydro Tools is used to fill sinks in the DEM.

(2) Calculating flow directions: the deterministic eight-node algorithm, D8, is the most widely used in judging flow direction. Its principle is as following: in a $3 \times 3$ local window, the water of the central grid will flows into the downstream grid with the greatest slope. The D8 algorithm has been embedded in the software ArcGIS .

(3) Generating flow accumulation matric: flow accumulation matric refers to the total water flow from all upstream grids whose flow directions are pointing to the goal grid.
(4) Extracting river networks: Based on the flow accumulation matric, it can generates stream nets by setting catchment area thresholds. The model Stream Definition in the ArcHydro Tools can achieve this function.

The experimental process for extracting topographic features of watershed is as figure 2 :

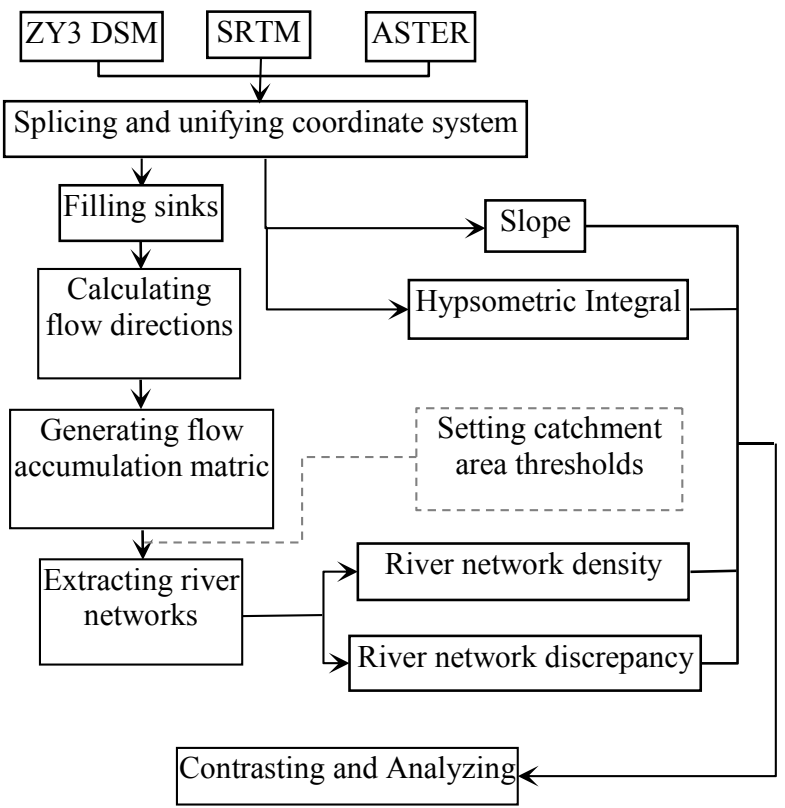

Figure 2. Flow chart of feature extraction

\section{EXPERIMENTAL RESULTS AND ANALYSIS}

\subsection{Slope}

Slope is a tilt indicator of local surface on the earth, and its size can affects the scale and intensity of surface material flow and energy conversion, and it is an important factor that restricts the spatial layout of productivity. The slope of a point equals to the angle between the normal vector $n$ of the point and the $Z$ axis.

$$
\text { Slope }=\arccos \left(\frac{z \cdot n}{|z| \cdot|n|}\right)
$$

It can be know that the distributions of slope extracted from different data sets are approximately the same from the figure 3 , the three data sets all can express the terrain of the study area.

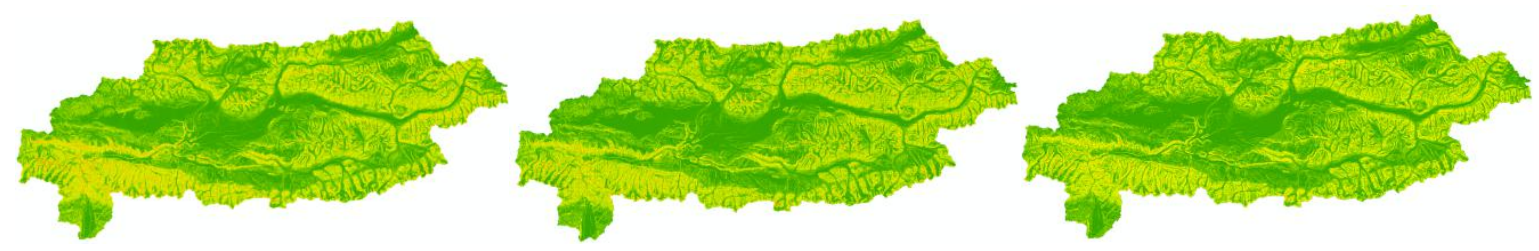

Figure 3. Slope graphs extracted from different data sources (left: ZY3 DSM; middle:SRTM; right: ASTER) 


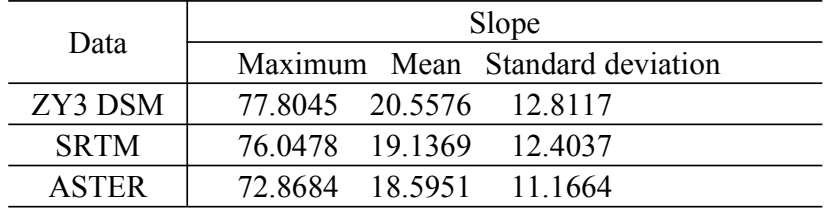

Table 1. Slope values under different data sources

As shown in table 1, the maximum, mean and standard deviation of slope extracted from ZY3 DSM is the greatest among those extracted from the three data sets, which indicates that SRTM and ASTER, to a certain extend, tend to flatten the watershed's topography. In order to analysis and compare slopes at different levels, slopes are divide into 8 levels at an equal interval--10 degree. The abscissa represents slope values, and the ordinate represents the percentage of total grids.

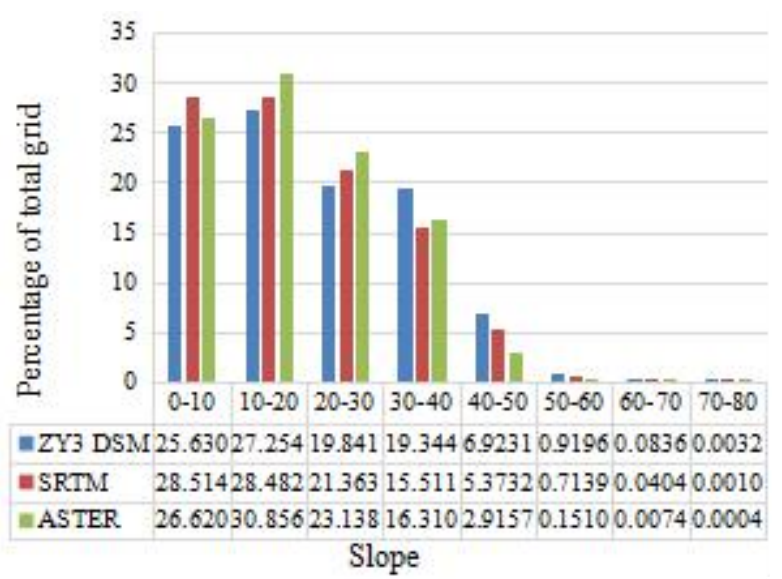

The result is shown as shown in figure 4: when slope value is greater than 30 degree, the count of ZY3 DSM is greater than those of SRTM and ASTER; when slope value is less than 10 degree, the count of ZY3 DSM is less than those of SRTM and ASTER. This result is consistent with the conclusion from table 1. ZY3 DSM can extract more subtle topographic features, and its effect is the best one, followed by SRTM, and the effect of ASTER is the worst one.

\subsection{Hypsometric Integral}

The elevation distribution curve is a cumulative curve, with the percentage of elevation as the vertical axis and the percentage of the area above the elevation as the abscissa axis. The area surrounded by the elevation distribution curve and the coordinate axes is equal to Hypsometric Integral, hereinafter referred to as HI (Zhou and Liu, 2016). HI expresses various stages of geomorphological evolution quantitatively, it is an important index to reveal the topography and development characteristics of the watershed.

The dashed line represents fitting curve of the solid line, and the equation corresponding to the dashed line is on the top of the curve. It can be seen that the trend of the three curves are roughly the same, and their value of $\mathrm{HI}$ are $0.4726,0.4719$ and 0.4757 respectively. According to the rule for dividing the development of the topography of a watershed:infancy $(\mathrm{HI}>0.6)$, maturity $(0.35<\mathrm{HI}<0.6)$ and topographic old age $(\mathrm{HI}<0.35)$, it can be concluded that the influence of different data sources on HI is very tiny, which can express that the watershed is in maturity.

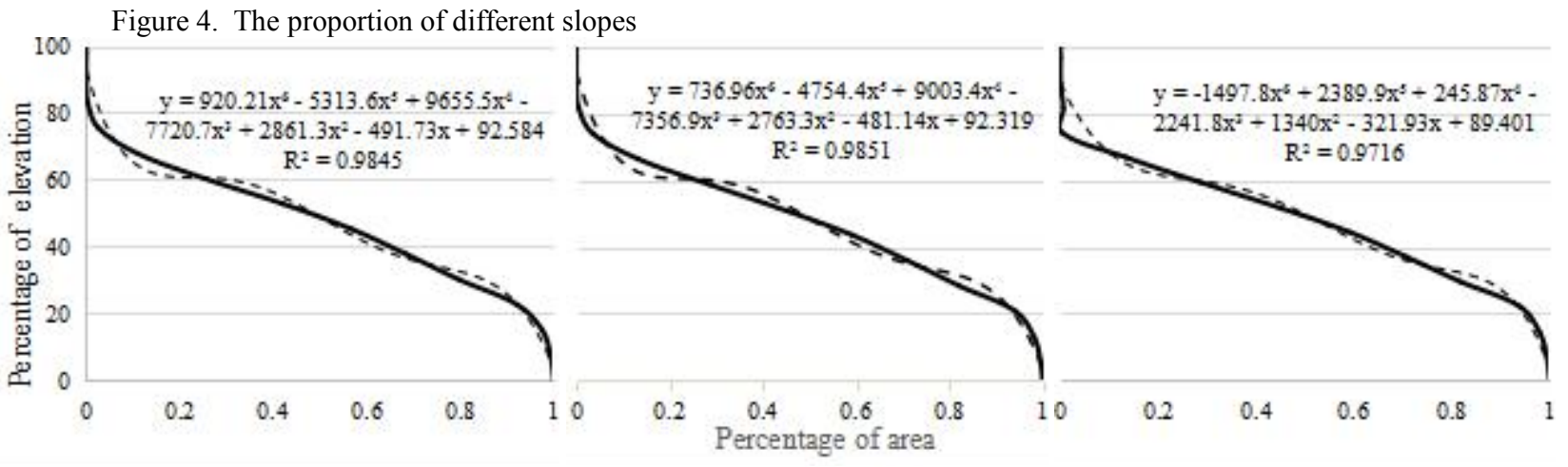

Figure 5. Elevation Distribution Curves (left: ZY3 DSM; middle:SRTM; right: ASTER)

\subsection{River network density}

The river network density is the length of a river within a unit area, that is, the ratio of the total length of the river network to the watershed area.The river network density can describe the degree of development of river systems. The calculation formula of river network density is as follows:

$$
D e=\frac{L}{S}
$$

Where $\mathrm{L}=$ total length of the river network

$\mathrm{S}=$ the area of watershed

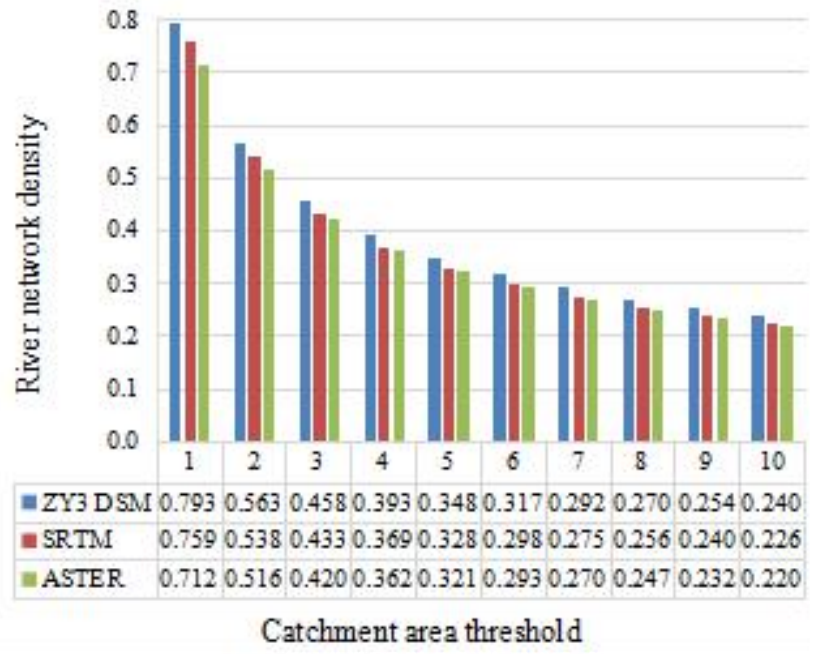

Figure 6. River networks density 
As shown in Figure 6, with the increase of catchment area threshold, the river network density extracted by the same data set is reduced. Under the same catchment area threshold, the relationship of river network density extracted by the three data sources is as follows: ZY3 DSM>SRTM>ASTER.In general, the river network density of ZY3 DSM is $4.4 \% \sim 6.0 \%$ larger than that of SRTM, and $7.5 \% \sim 10.2 \%$ larger than that of ASTER.

\subsection{River network discrepancy}

In order to describe the degree of coincidence of different river networks quantitatively, the concept of river network discrepancy is introduced (Zhan, 2008). The calculation formula of river network discrepancy is as follows:

$$
D \mathrm{c}=\frac{\sum A_{i}}{S} \times 100 \%
$$

Where $A_{i}=$ the area of the fine-grained polygon produced by the superposition of two river networks $\mathrm{S}=$ the area of watershed

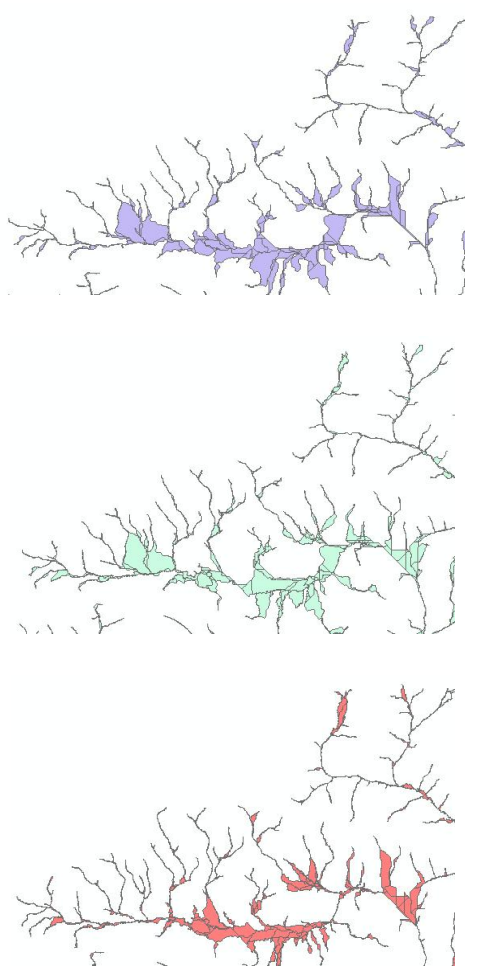

Figure 7. Parts of river network discrepancy curves

(Catchment area threshold is $1 \mathrm{~km}^{2}$; upper: ASTER- SRTM; middle: ASTER-ZY3 DSM; lower: SRTM-ZY3 DSM)

From figure 7, the river networks extracted from ZY3 DSM has the highest similarity with those from SRTM at a visual analysis of the river network discrepancy curves above, and as figure 8 shown, ZY3 DSM and SRTM have the smallest river network discrepancy under the same catchment area threshold.

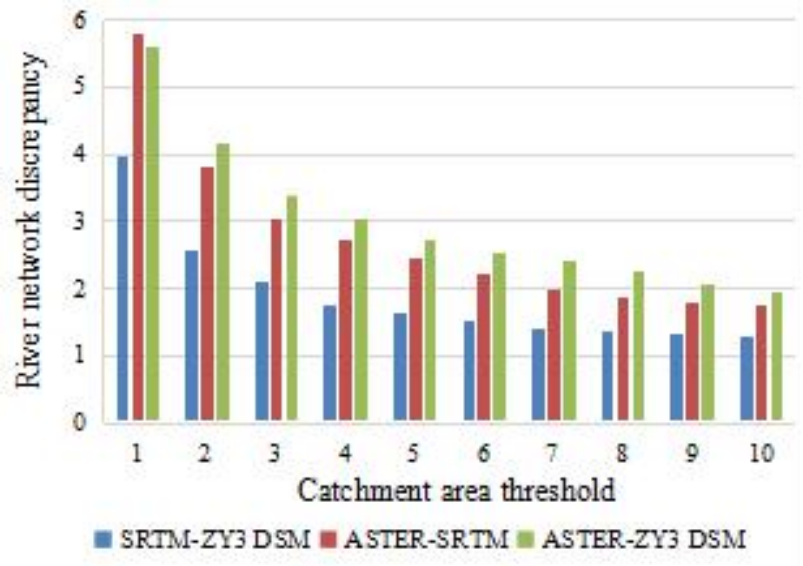

Figure 8. River networks discrepancy

The river network discrepancy between ASTER and ZY3 DSM is the biggest among the three except when the catchment area threshold is $1 \mathrm{~km}^{2}$. The larger river network discrepancy, the lower similarity of the two rivers, and the smaller river network discrepancy, the higher similarity of the two rivers. So it can conclusion that the similarity between ZY3 DSM and SRTM is the highest one, but the similarity between ZY3 DSM and ASTER is the lowest one from all the results above.

\section{CONCLUSIONS}

The terrain of malyy naryn river watershed is complex and affected by various factors. This article discussed four feature factors (slope, hypsometric integral, river network density and river network discrepancy) based on ZY3 DSM, SRTM and ASRTER. From the analysis above, the following conclusions can be drawn:

(1) From slope map and HI, it can be know that ZY3 DSM, SRTM and ASTER can express the same rough terrain characteristics, at the same time, degree of watershed topography development expressed by different data sets are consistent.

(2) From the analysis of slope and river network density, ZY3 DSM can reflect terrain information over the Malyy Naryn River watershed in most detail and it has the best expression effect on the terrain among the three data sets of ZY3 DSM, SRTM and ASTER, followed by SRTM, and the effect of ASTER is the worst.

(3) The similarity of river networks extracted by ZY3 DSM and SRTM is the highest one, but the similarity between ZY3 DSM and ASTER is the lowest one from river network discrepancy curves and $\mathrm{HI}$.

\section{REFERENCES}

Guo, X.Y., Zhang, H.Y., Zhang, Z.X., Hou, G.L.,and Zhao, J.J.,2011. Comparison analysis of data quality accuracy between ASTER GDEM and SRTM3. Remote Sensing Technology and Application, 26 (03), pp. 334-339.

Jobin Thomas, Sabu Joseph, K. P. Thrivikramji, K.S., and Arunkumar., 2014. Sensitivity of digital elevation models: The scenario from two tropical mountain river basins of the Western Ghats, India. Geoscience Frontiers, 5(6), pp. 893-909. 
Li, D.R.,2012. Chinese first civilian three-line array stereo mapping satellite--Ziyuan3 satellite. Acta Geodaetica et Cartographica Sinica,41(3), pp. 317-322.

Ma, L.Y., Zhou, C.P., Hu, Z.J., Wang, Z.H., and Ma, G.B., 2011. Research on extraction of river networks in Liaohe watershed based on SRTM DEM and ASTER GDEM. Journal of Anhui Agricultural Sciences, 39(05), pp. 2692-2695.

O'Callaghan, J. F. and Mark, D.M., 1984. The Extraction of drainage networks from digital elevation data. Computer Vision, Graphics and Image Processing, 28(4), pp. 323-344.

Ren, Y., Zhang, F., Wang, J., Zhang, Y.,and Li, R., 2018. Comparison of simulated river networks in the Ebinur Lake watershed based on different DEM data sets. Science of Surveying and Mapping, 2018(03), pp. 1-12.

Solomon Vimal, 2012. Extraction of Drainage Pattern from ASTER and SRTM Data for a River Basin using GIS Tools. Asia-Pacific Chemical,Biological \& Environmental Engineering Society(APCBEES).Proceedings of 2012 International Conference on Environment,Energy and Biotechnology.,2012:5.

Tang, X.M., Zhang, G., and Zhu, X.Y., 2012. Construction and accuracy verification of the ZY3 mapping satellite three-line array imaging geometric model. Acta Geodaetica et Cartographica Sinica,41(2), pp. 191-198.

Wu, W.J., Zhang, S.F., and Zhao, S.M., 2017. Comparative analysis of SRTM1 DEM and ASTER GDEM V2. GeoInformation Science, 19(08), pp. 1108-1115.

Zhou, Q.M., and Liu, X.J., 2016. Digital Terrain Analysis. Science Press, Beijing, pp. $30-32$.

Zhan, Lei., 2008. Accuracy evaluation and applicability of SRTM DEM: A case study in Shaanxi Province. Nanjing Normal University, Nanjing, Jiangsu, China, pp. 62-63. 